\title{
Trauma medular em cães e gatos: revisão da fisiopatologia e do tratamento médico
}

\section{Spinal cord trauma in dogs and cats: revision of pathophysiology and medical treatment}

\author{
Mônica Vicky Bahr Arias ${ }^{1 *}$; Maíra Santos Severo², Eduardo Alberto Tudury ${ }^{3}$
}

\section{Resumo}

\begin{abstract}
O trauma medular é uma das entidades neurológicas mais freqüentes e mais graves na prática clínica. A lesão medular aguda inicia uma seqüência de eventos vasculares, bioquímicos e inflamatórios que resultam no desenvolvimento de lesões teciduais secundárias, levando à destruição progressiva do tecido neuronal com conseqüências desastrosas e freqüentemente irreversíveis às funções motora e sensorial do animal. Esta afecção deve ser considerada emergencial, visto que a intervenção rápida e adequada em intervalo de tempo apropriado, pode limitar a extensão dos danos ao tecido neuronal, favorecendo assim a recuperação neurológica do paciente. Em geral, no tratamento da lesão medular aguda são utilizados agentes neuroprotetores, visando o controle das lesões secundárias, associados ou não à cirurgia para descompressão e estabilização da coluna vertebral. A compressão medular crônica pode ser decorrente de processos que se desenvolvem gradativamente, mas também pode se referir a seqüelas decorrentes dos efeitos do trauma, meses a anos após a ocorrência da lesão. O objetivo deste trabalho é revisar a fisiopatologia do trauma medular, o tratamento médico disponível, as opções para o futuro e as controvérsias existentes sobre o uso de alguns fármacos.
\end{abstract}

Palavras-chave: Medula Espinhal, cães, gatos

\begin{abstract}
Spinal cord trauma is one of the most frequent and serious neurologic entity in clinical practice, due to its production of lesions. Acute spinal cord injury initiates a sequence of vascular, biochemical and inflammatory events that can take to disastrous and frequently irreversible consequences to the motor and sensorial function of the animal. Acute spinal cord trauma should be considered an emergency and fast and appropriate intervention, in an appropriate interval of time, can limit the extension of the damage to the neuronal tissue, favoring neurological recovery. In general, the treatment of spinal cord involves the use of neuroprotective agents to control secondary lesions; and to perform surgery aiming decompression of the injured spinal cord, accomplishing or not the stabilization of the spine. Chronic spinal cord compression may be secondary to diseases that develops gradually, or refers to the effects of spinal cord trauma in the months to years after the acute injury. The main purpose of this paper was to revise the pathophysiology of spinal cord trauma, the medical treatment available, the options for the future and the controversies about the use of some drugs.
\end{abstract}

Key words: Spinal Cord, dogs, cats

\footnotetext{
1 Médica Veterinária, Mestre e Doutora, Professora Adjunta, Departamento de Clínicas Veterinárias, Universidade Estadual de Londrina (UEL). E-mail: vicky@uel.br

2 Médica Veterinária mestranda, Universidade Federal Rural de Pernambuco (UFRPE) e-mail: mairasevero@yahoo.com.br.

3 Médico Veterinário, Mestre e Doutor, Professor Adjunto 3, Departamento de Medicina Veterinária (DMV), Universidade Federal Rural de Pernambuco (UFRPE), Rua Dom Manuel de Medeiros s/n, Dois Irmãos, Recife, Pernambuco, Brasil.CEP: 52171-900. e-mail: oceanos@hotlink.com.br.

* Autor para correspondência
} 


\section{Introdução}

A lesão da medula espinhal ocorre comumente em cães e gatos devido a causas exógenas ou endógenas (BAGLEY et al., 1999). A lesão de origem endógena geralmente decorre de extrusão ou protrusão de disco intervertebral, fraturas patológicas, anormalidades congênitas e instabilidade. Fatores exógenos incluem traumas automobilísticos, projéteis (lesões por armas de fogo), quedas e lesões provocadas por outros animais e por objetos (SHORES; BRAUND; BRAWNER, 1990; SHORES, 1992; MEINTJES; HOSGOOD; DANILOFF，1996; BAGLEY，1999; PLATT; ABRAMSON; GAROSI, 2005).

A lesão medular pode resultar em incapacidade permanente e seu tratamento ainda permanece um desafio tanto para a medicina humana como veterinária (BLIGHT, 2000), pois além dos neurônios no sistema nervoso central não regenerarem (JEFFERY et al., 2001), não há consenso sobre o tratamento ideal (OLBY; JEFFERY, 2003). O conhecimento e a utilização precoce de medicamentos e/ou procedimentos cirúrgicos específicos, que preservem a integridade estrutural do neurópilo medular, pode fazer a diferença entre o retorno à deambulação ou paralisia. O objetivo desta revisão é abordar a fisiopatologia e o tratamento dos traumas medular agudo e crônico e discutir as controvérsias existentes sobre o uso de alguns fármacos.

\section{Fisiopatologia do Trauma e da Compressão Aguda}

O trauma medular agudo resulta em lesão por meio de dois mecanismos. A lesão primária é decorrente das forças que causam dano mecânico instantaneamente após o evento traumático, tais como compressão, transecção, laceração, flexão e tração (BERGMAN et al., 2000 b). Ocorre no momento do trauma e envolve a ruptura e o esmagamento de elementos neuronais e vasculares (COUGHLAN, 1993; BRAUND, 1994). Inclui a ruptura de axônios, corpos celulares nervosos e estruturas de suporte (células da glia) resultando em interrupção fisiológica e/ou morfológica dos impulsos nervosos (RUCKER, 1990; BAGLEY et al.; 1999).

A lesão secundária desenvolve-se minutos a dias após o trauma, devido a alterações locais intracelulares e extracelulares, associada a lesões sistêmicas como hemorragia, hipóxia e outras decorrentes do trauma (JANSSENS, 1991; BRAUND, 1994; LECOUTER, 1998). O traumatismo inicial pode deflagrar uma cascata de eventos destrutivos que causam a perda do tecido neuronal inicialmente não comprometido (COUGHLAN, 1993; BERGMAN et al., 2000 b). Várias alterações sistêmicas, focais e celulares caracterizam as lesões secundárias, resultando em mudanças biomecânicas e patológicas que podem causar deterioração funcional e comprometer a integridade estrutural da medula espinhal (SHORES, 1992; MEINTJES; HOSGOOD; DANILOFF; 1996; BERGMAN et al., 2000 b; OLBY; JEFFERY, 2003).

Existem quatro mecanismos básicos na lesão aguda à medula espinhal: interrupção anatômica, compressão, concussão e isquemia. A interrupção anatômica do parênquima da medula espinhal é a laceração física do tecido nervoso, cujos efeitos são considerados como não tratáveis e irreversíveis (KRAUS, 2000). A compressão medular decorrente da presença de uma massa conduz ao aumento da pressão no interior do canal vertebral. É comumente causada por extrusão de disco ou tumores, acometendo primeiramente a substância branca da medula espinhal (BAGLEY et al, 1999; KRAUS, 2000). A quantidade de compressão medular decorrente da extrusão de disco é determinada pela massa do núcleo extruso degenerado dentro do canal, da proporção do diâmetro do canal vertebral em relação ao diâmetro da medula espinhal e da quantidade relativa de desidratação do disco intervertebral degenerado (SHORES, 1992). As lesões medulares na região torácica, por exemplo, costumam ser mais severas, devido ao reduzido tamanho do lúmen do canal espinhal (BERGMAN et al., 2000 b). 
A concussão decorre de um impacto agudo à medula espinhal, geralmente sem compressão residual, afetando inicialmente a substância cinzenta da medula espinhal, propagando-se para a substância branca e podendo levar a destruição progressiva do tecido nervoso (KRAUS, 2000). Isquemia é a interrupção do suprimento sanguíneo arterial para a medula espinhal (COUGHLAN, 1993). Este processo está relacionado à perda da auto-regulação do fluxo sangüíneo no segmento medular lesionado (FRANCEL et al., 1993) e sua extensão depende da severidade da lesão inicial, sendo de caráter progressivo (JEFFERY, 1995).

$\mathrm{Na}$ prática clínica é difícil classificar as lesões, pois elas não ocorrem de forma isolada. Por exemplo, uma extrusão de disco intervertebral pode causar concussão, isquemia transitória e compressão pela presença do material no interior do canal medular. Já quando ocorre uma fratura, a lesão inicial causa lesão do parênquima e concussão, enquanto os fragmentos ósseos ou a instabilidade vertebral e desalinhamento das vértebras podem causar compressão medular, sendo que cada uma dessas lesões favorece a ocorrência e propagação de outras, exacerbando o quadro neurológico (KRAUS, 2000).

\section{Efeitos imediatos do trauma}

Após o impacto à medula espinhal, existe um bloqueio total da condução nervosa devido ao influxo de potássio advindo das células lesadas mecanicamente. A mudança da quantidade de potássio extracelular e intracelular promove a despolarização e conseqüente bloqueio da condução (JANSSENS, 1991; JEFFERY, 1995; OLBY; JEFFERY, 2003).

\section{Anormalidades vasculares}

Em seguida ao trauma ocorre perda da autoregulação do fluxo sangüíneo no segmento medular lesado e a pressão de perfusão torna-se diretamente relacionada à pressão arterial sistêmica, que na maioria das vezes está baixa devido às lesões sistêmicas concomitantes (COUGHLAN, 1993; CAMBRIDGE; BAGLEY, 1997; OLBY, 1999). O fluxo sangüíneo na substância cinzenta reduz-se drasticamente durante as primeiras duas horas e permanece em níveis baixos dentro das primeiras 24 horas (JANSSENS, 1991; COUGHLAN, 1993; JEFFERY, 1995 b). O fluxo sangüíneo na substância branca também diminui inicialmente, dentro de uma a seis horas após a lesão, mas retorna ao normal, podendo, de acordo com alguns estudos, aumentar dentro de 24 horas (JEFFERY, 1995 b).

O aumento da concentração de substâncias vasoconstritoras (como por exemplo a prostaglandina PGF2 $\alpha$ e o tromboxano $A_{2}$ ) no segmento lesado, somado à hipotensão sistêmica que ocorre após o trauma, pode causar o declínio do fluxo sangüíneo medular, levando à isquemia neuronal (JERRAM; DEWEY, 1999). O tromboxano $A_{2}$, além de ser um potente vasoconstritor, facilita fortemente a agregação plaquetária, comprometendo assim a microcirculação (RUCKER, 1990; COUGHLAN, 1993). O decréscimo da perfusão na área lesada reduz o suprimento de oxigênio e energia para os neurônios e células da glia, causando dano à membrana celular, levando ao aumento da sua permeabilidade e conseqüente penetração de fluidos, componentes sangüíneos e substâncias lesivas aos neurônios (KRAUS, 2000; OLBY; JEFFERY, 2003).

Logo após lesão concussiva severa, a hemorragia que ocorre na substância cinzenta também causa decréscimo generalizado no fluxo sangüíneo medular (JEFFERY, 1995 b). A isquemia decorrente da lesão concussiva afeta principalmente a substância cinzenta da medula espinhal, pois esta parte da medula espinhal, mais vascularizada, possui maior exigência de oxigênio e glicose quando comparado à substância branca (RUCKER, 1990).

A necrose hemorrágica traumática inicia-se na substância cinzenta e se propaga para a substância branca. Li, Brodin; Farooque (1996) demonstraram a ocorrência de morte programada ou apoptose, que resulta 
em perda progressiva das células do parênquima da medula espinhal, primariamente oligodendrócitos. A perda destas células reduz os níveis de mielina dos axônios, resultando em disfunção. A privação de fatores tróficos parece ser a causa da ocorrência de apoptose nos oligodendrócitos e neurônios motores (LI; BRODIN; FAROOQUE, 1996).

A compressão medular pode exacerbar os eventos isquêmicos da lesão concussiva, à medida que ocorre edema vasogênico associado ao aumento da pressão intraparenquimatosa. O edema ocorre devido à obstrução da drenagem venosa e mudanças na permeabilidade dos vasos (OLBY; JEFFERY, 2003), o que por sua vez causa comprometimento da substância cinzenta e leva a transtornos nos axônios e exposição dos oligodendrócitos a agentes lesivos, exacerbando a apoptose celular (KRAUS, 2000). Como a medula espinhal situa-se dentro de um canal vertebral não expansivo, a compressão tende a distribuir pressão transversalmente por todo o seu parênquima, comprometendo sua função, porém a substância cinzenta é relativamente preservada nesse processo. A habilidade da medula espinhal em regular o fluxo sangüíneo e os níveis de dióxido de carbono diminui. A medula espinhal tenta preservar-se, perdendo mielina e axônios da substância branca, para acomodar o material compressivo (KRAUS, 2000).

\section{Eventos bioquímicos}

Em associação à redução do fluxo sangüíneo na medula espinhal, ocorrem mudanças metabólicas severas momentos após a ocorrência da lesão (BRAUND, 1993). Normalmente a concentração de L-glutamato, um neurotransmissor excitatório, é regulada por um mecanismo ativo e eficiente efetuado por astrócitos. O dano mecânico aos neurônios, associado à falta de energia local, leva ao aumento da liberação neuronal de glutamato e decréscimo da ação do mecanismo dos astrócitos sobre o mesmo, elevando a concentração deste neurotransmissor a níveis tóxicos. A interação do L-glutamato com o receptor $\mathrm{N}$-metil D-aspartato (NMDA), um receptor para o L glutamato nas membranas pós-sinápticas (JANSSENS, 1991; COUGHLAN, 1993; JEFFERY, 1995 b; OLBY, 1999), abre os canais de íons, ocasionando o aumento intracelular de sódio, cloreto e principalmente cálcio (JEFFERY, 1995 b; OLBY; JEFFERY, 2003).

O aumento da concentração do cálcio intracelular ativa proteases como a calpaína e a caspase, que destroem o citoesqueleto e o DNA cromossomal, iniciando a necrose (calpaína) e a apoptose (calpaína e caspase). Isto ativa também a fosfolipase $A_{2}$ produzindo assim eicosanóides, iniciando a resposta inflamatória (BARTHOLDI; SCHWAB, 1997; OLBY, 1999). A ativação da fosfolipase $A_{2}$ desencadeia a produção de leucotrienos, tromboxanos, histamina e prostaglandinas. O aumento dos níveis de prostaglandinas causa o aumento da permeabilidade vascular e vasoconstricção ou vasodilatação. Ocorre também alteração da função plaquetária, que pode causar obstrução de vasos sangüíneos e liberação de serotonina (5HT - 5 hidroxitriptamina), a qual também ativa a permeabilidade vascular, favorecendo a formação de edema (JANSSENS, 1991).

\section{Peroxidação lipídica}

Durante o evento isquêmico há um esgotamento das reservas de adenosina trifosfato (ATP) e um acúmulo de produtos do metabolismo celular, levando à produção de radicais livres. Os radicais livres são moléculas muito reativas e instáveis, que são desativadas geralmente por um sistema varredor de radicais livres e por outros antioxidantes (CAMBRIDGE; BAGLEY, 1997). Estas moléculas atacam preferencialmente a porção fosfolipídica da membrana celular, desencadeando o processo denominado "peroxidação lipídica" (BRAUGHLER; HALL, 1989; OLBY, 1999), ocorrendo lesão dos neurônios e células da glia (OLBY, 1999). Este processo leva a produção de radicais livres de lipídios e ácidos graxos e redução dos níveis de antioxidantes endógenos como o alfa-tocoferol (BRAUND, 1993). 
A "peroxidação lipídica" prejudica a atividade de enzimas neuronais chave como a adenosina trifosfato, responsável pela manutenção do potencial de repouso neuronal (BRAUGHLER; HALL, 1989). Este processo é acelerado por catalisadores como ferro, cobre e produtos da degradação da hemoglobina como a hematina (ANDERSON et al.; 1985; BRAUND; SHORES; BRAWNER JR.; 1990).

\section{Reação inflamatória}

A lesão traumática ao SNC desencadeia rapidamente uma resposta inflamatória contribuindo para a lesão secundária que se desenvolve após o impacto inicial (OLBY; JEFFERY, 2003). Tal resposta inflamatória resulta na produção de uma variedade de citotoxinas e agentes protetores. As células microgliais liberam citocinas, interleucina-1, fator alfa de necrose tumoral e produtos tóxicos potentes como o peróxido de hidrogênio, óxido nítrico e proteinases, minutos após a ocorrência da lesão (OLBY; JEFFERY, 2003). Os mediadores inflamatórios têm efeitos prejudiciais na condução iônica e transmissão sináptica, alterando a função neuronal (SMITH; McDONALD, 1999).

Ocorrem duas fases de infiltração celular durante o desenvolvimento da resposta inflamatória na lesão medular. Inicialmente há um influxo de neutrófilos que atingem níveis máximos dentro de poucas horas, havendo então o posterior recrutamento de macrófagos cujo pico é estabelecido após cinco a sete dias (DUSART; SCHWAB, 1994). Esta segunda fase de infiltração celular coincide com a desmielinização secundária e perda de axônios (OLBY; JEFFERY, 2003).

$\mathrm{Na}$ medula espinhal lesada pode-se constatar a presença de leucócitos polimorfonucleares fagocíticos no interior e adjacente às paredes vasculares e às áreas de hemorragia, sugerindo a possibilidade do trauma induzir a ativação das lipases das membranas, hidrolizando os fosfolipídeos das mesmas e liberando vários ácidos graxos, mais notadamente o ácido araquidônico. (OLBY; JEFFERY, 2003).

\section{Opióides e receptores opiáceos}

Braund, Shores e Brawner Jr., (1990) e Olby (1999) verificaram que os opióides endógenos contribuem para a ocorrência de isquemia, através de sua influência no fluxo sangüíneo da microcirculação da medula espinhal. Os opióides endógenos elevam os níveis de endorfinas resultando em hipotensão sistêmica. A hipotensão reduz o fluxo sangüíneo na medula espinhal e agrava a isquemia (BERGMAN et al.; 2000 b). Braund (1993) sugeriu que a dinorfina, um opióide endógeno derivado da pró-encefalina beta, tem seletividade pelo receptor opióide kappa e pode ser o fator opióide patológico no trauma medular.

\section{Fisiopatologia da Compressão Crônica}

A medula pode suportar um certo grau de compressão antes do aparecimento de alterações neurológicas. Esta variação depende da velocidade com que a compressão ocorre e localização da mesma. A compressão crônica pode decorrer de neoplasias de crescimento lento, protrusão crônica de disco intervertebral, ou de doenças congênitas e degenerativas das vértebras, como por exemplo a espondilomielopatia cervical caudal (OLBY; JEFFERY, 2003). Muitas vezes pode haver sobreposição das lesões, ocorrendo lesão contusa aguda e compressão crônica.

Neste tipo de compressão existem várias diferenças fisiológicas, quando comparado às desordens concussivas agudas (PLATT; ABRAMSON; GAROSI, 2005). Na compressão crônica, o fluxo sangüíneo e os níveis de oxigênio são freqüentemente mantidos na medula espinhal. A principal alteração que ocorre nestes casos é a desmielinização e edema axonal, e somente mais tarde a substância branca se torna edemaciada devido à ocorrência de edema vasogênico, o que por sua vez aumenta a compressão medular (PLATT; ABRAMSON; GAROSI, 2005). Quando pequeno volume de material discal prolapsa para o interior do canal vertebral, há produção de uma força dinâmica 
mínima, levando assim a sinais clínicos brandos. $\mathrm{Na}$ compressão crônica a força dinâmica é baixa e a medula espinhal pode lançar mão de mecanismos compensatórios ao deslocamento que se desenvolveu, induzindo mudanças em sua forma. Quando a compressão supera este mecanismo, desenvolve-se hipóxia local, assim como desmielinização, degeneração axonal e malácia (TOOMBS; WATERS, 2003).

Dois fatores são responsáveis pelos sinais clínicos vistos na compressão medular crônica: a força mecânica direta e o suprimento sangüíneo comprometido. A deformidade mecânica é facilmente produzida na medula espinhal por esta ser constituída por tecido macio e delicado, e a força mecânica é capaz de alterar a condução normal de impulsos nervosos (KRAUS, 2000; JEFFERY, 1995). O edema é uma seqüela comum observada na compressão medular, provavelmente em parte pela oclusão da drenagem dos vasos (OLBY; JEFFERY, 2003). É questionável se o bloqueio das artérias é fator importante na compressão medular crônica, pois em micro-angiografias não foi observado tal efeito (VANDEVELDE; WOLF, 1993).

As diferenças entre os mecanismos das lesões aguda e crônica à medula espinhal podem estar relacionadas ao tipo de vaso afetado pela lesão. Durante a doença compressiva crônica, as veias são preferencialmente afetadas (JEFFERY, 1995). Há o predomínio de lesões como desmielinização e degeneração walleriana nos tratos espinhais da substância branca, porém também pode existir dano à substância cinzenta, provavelmente devido à isquemia progressiva. $\mathrm{O}$ mecanismo de lesão isquêmica à medula espinhal na doença compressiva é similar à que acontece na lesão concussiva aguda; entretanto ocorre mais lentamente, sendo então mais sensível à intervenção médica e cirúrgica (JEFFERY, 1995).

Por outro lado, a lesão medular crônica também pode se referir aos efeitos do trauma meses a anos após a lesão medular aguda (BERGMAN et al., 2000 a), principalmente desmielinização (BLIGHT, 2000). Os avanços nos cuidados médicos, no controle das infecções secundárias que podem se desenvolver após o trauma e a capacidade de lidar com todas as complicações da lesão medular promoveu o aumento da sobrevida dos pacientes com este tipo de lesão, incentivando a pesquisa de terapias para a desmielinização crônica (BLIGHT, 2000).

No esquema 1 encontra-se a seqüência dos principais eventos vasculares, bioquímicos e inflamatórios envolvidos na lesão concussiva e compressiva à medula espinhal de cães e gatos.

\section{Tratamento da Lesão Aguda à Medula Espinhal}

O médico veterinário deve sempre considerar a lesão medular aguda uma emergência e a instituição rápida do tratamento é fator crítico na limitação da degeneração e necrose do tecido neuronal. A prioridade no tratamento de todo paciente politraumatizado é a estabilização do estado geral, controlando qualquer condição que ameace a vida, como a hipotensão e hipotermia (COUGHLAN, 1993; LANZ; BERGMAN; SHELL, 2000), pois estas podem influenciar no exame neurológico subseqüente (BAGLEY et al.; 1999).

Após a estabilização do paciente, deve-se realizar exame físico e clínico meticuloso, observando principalmente a função respiratória, freqüência e ritmo cardíaco, grau de perfusão capilar, capacidade de realizar movimentos voluntários e o nível de consciência (BAGLEY et al., 1999). O animal deve ser mantido imobilizado em uma maca, evitando deslocamento de fraturas ou luxações espinhais instáveis, visando diminuir nova ocorrência de lesão primária se houver instabilidade vertebral, (Figuras 1 e 2) (SHORES; BRAUND; BRAWNER, 1990; LANZ; BERGMAN; SHELL, 2000). Isto pode ser feito colocando-se o paciente sobre uma superfície lisa e rígida, em decúbito lateral, com auxílio de fita adesiva (LANZ; BERGMAN; SHELL; 2000). 


\section{TRAUMA ESPINHAL AGUDO \\ COMPRESSÃO E CONCUSSÃO}

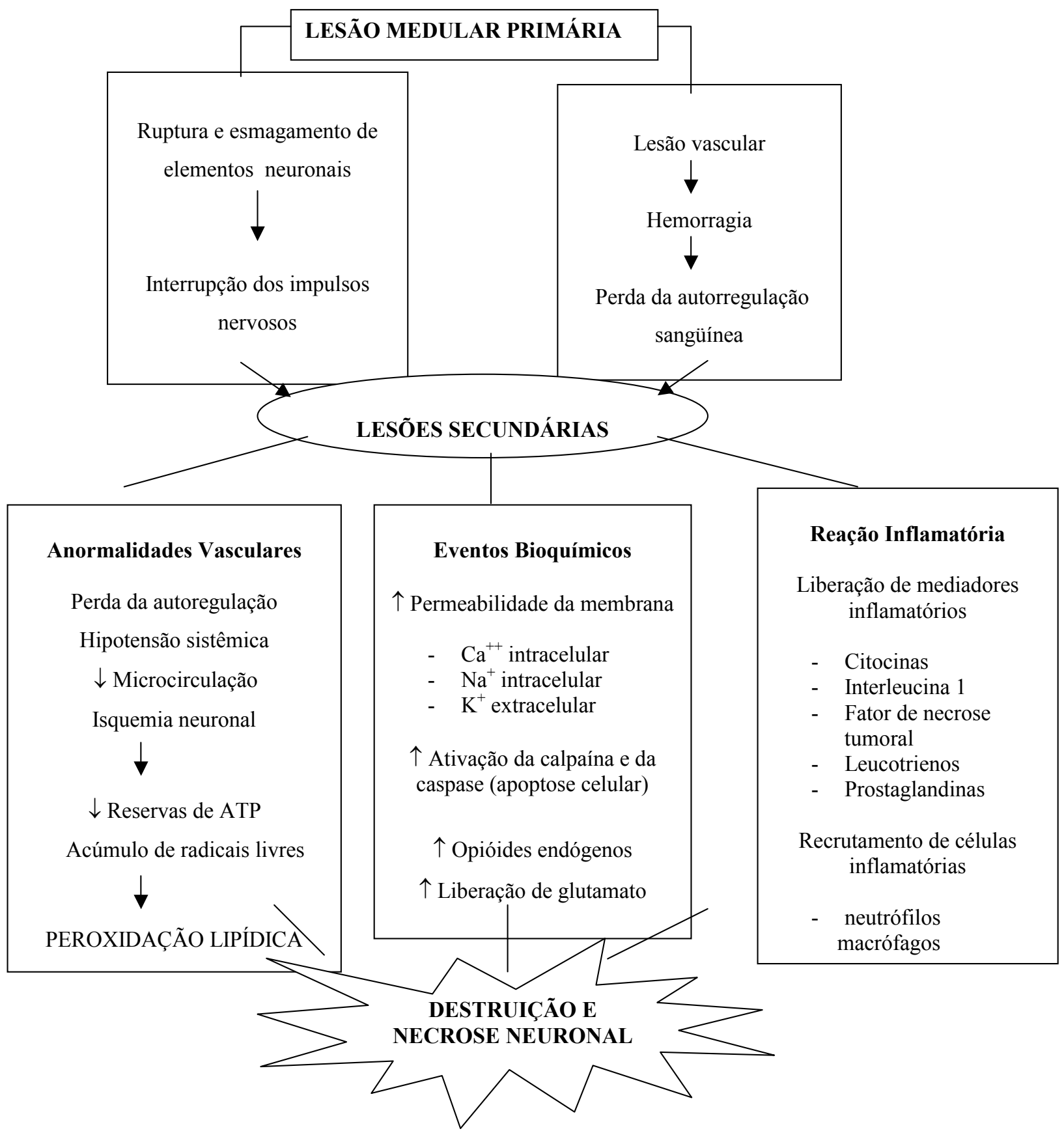

Esquema 1. Principais eventos vasculares, bioquímicos e inflamatórios envolvidos no trauma agudo à medula espinhal de cães e gatos. 


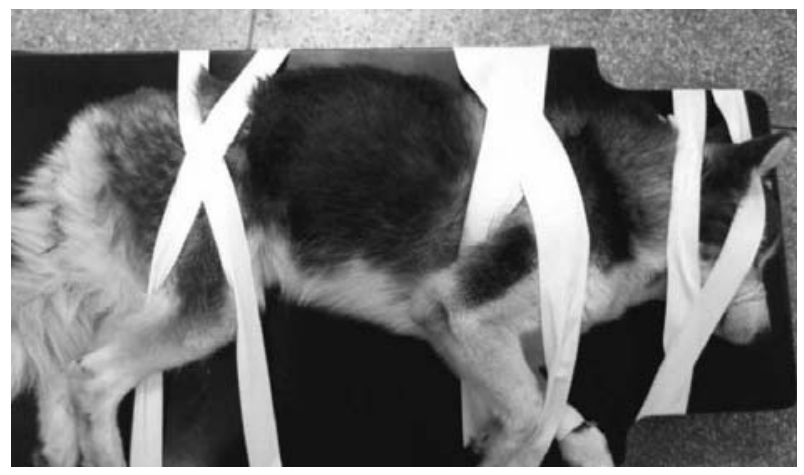

Figura 1. Imobilização de paciente com suspeita de trauma medular cervical.

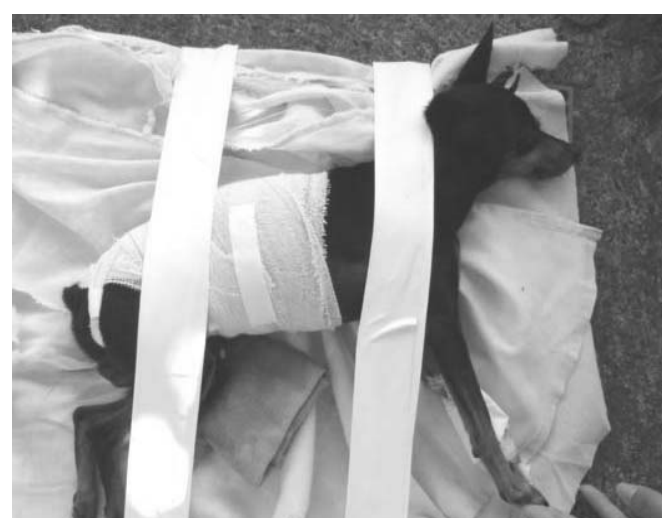

Figura 2. Imbobilização de paciente com trauma medular toracolombar

Mesmo com o animal imobilizado é importante executar um cuidadoso exame neurológico para localizar o segmento medular afetado e determinar o grau de severidade da lesão (LANZ; BERGMAN; SHELL, 2000). Na escolha do tratamento adequado deve-se considerar o tipo e a gravidade da lesão da medula espinhal, sendo que esta é detectada pelo exame neurológico (STURGES ; LECOUTER, 2002). Muitas vezes a alteração é tão discreta que a função normal pode retornar sem qualquer tratamento (JEFFERY; BLAKEMORE, 1999). Outro fator a ser considerado é o tempo de ocorrência do trauma, visto a terapia neuroprotetora só ser eficaz quando administrada dentro de um tempo restrito (JEFFERY; BLAKEMORE, 1999).

Embora o clínico não tenha controle sobre o trauma inicial, o tratamento médico instituído deveria ser capaz de: influenciar a sobrevivência neuronal interrompendo os eventos fisiopatológicos
(COUGHLAN, 1993), prevenir a destruição bioquímica do tecido nervoso, diminuir o edema medular e controlar a hemorragia intra e extramedular. $\mathrm{O}$ tratamento cirúrgico não será abordado nesta revisão, mas sua escolha depende da presença de sinais neurológicos graves, evidência de compressão medular, presença de fratura estável que não responde ao tratamento conservador, piora dos sinais após instituição de tratamento conservador ou presença de instabilidade vertebral. Envolve o alívio da compressão medular por meio da remoção de fragmentos ósseos ou do material de disco existentes dentro do canal medular, e o alinhamento e a estabilização vertebral (MEINTJES; HOSGOOD; DANILOFF, 1996; STURGES; LECOUTER, 2002).

\section{Neuroprotetores}

O tratamento médico de cães e gatos com lesão medular é controverso, envolvendo o uso de protocolos adotados da medicina humana, pois faltam resultados de estudos prospectivos em medicina veterinária (OLBY, 2001). O uso de neuroprotetores é indicado (JEFFERY; BLAKEMORE, 1999) visando prevenir ou limitar a lesão secundária da medula espinhal (OLBY; JEFFERY, 2003). Existem inúmeros agentes farmacológicos para o tratamento da lesão medular, e muitos pontos de vista opostos sobre a eficácia destes agentes. A seguir serão abordados os principais neuroprotetores utilizados em estudos e na prática clínica, como bloqueadores de canais de cálcio, antioxidantes e varredores de radicais livres, e os inibidores do ácido araquidônico, dentre outros.

\section{Bloqueadores de canais de cálcio e sódio}

Os íons $\mathrm{Ca}^{2+}$ têm papel importante no desenvolvimento da isquemia após o trauma, sugerindo que a utilização de bloqueadores dos canais de cálcio possa ser útil na terapia da lesão medular (BRAUND, 1993; LECOUTER, 1998). O 
bloqueador de canais de cálcio nimodipine mostrou eficácia no tratamento de lesões medulares, ao melhorar o fluxo sangüíneo e a função dos axônios após o trauma (OLBY, 1999). Este agente bloqueia o aumento do cálcio intracelular, impedindo a ativação da fosfolipase $A_{2}$, que por sua vez inicia a cascata do ácido araquidônico e leva à peroxidação dos lipídios da membrana celular da medula (BERGMAN et al., 2000 a). Ao se utilizar o nimodipine em ratos na dosagem de $0,02 \mathrm{mg} / \mathrm{kg}$ em infusão contínua, por uma hora, e na dosagem de $0,02 \mathrm{mg} / \mathrm{kg} / \mathrm{h}$ IV por duas horas e $0,04 \mathrm{mg} / \mathrm{kg} / \mathrm{h} \mathrm{IV}$ por uma semana em babuínos, observou-se melhora moderada da função motora, quando comparado com a metilprednisolona (OLBY, 1999), não havendo diferença estatística significativa entre os tratamentos (LECOUTER, 1998). A utilização de colóides, em combinação com nimodipine, preveniu a hipotensão sistêmica que pode acompanhar o uso de bloqueadores de canais de cálcio (JEFFERY; BLAKEMORE, 1999).

O pré-tratamento com diltiazem, na dose de $100 \mu \mathrm{g} / \mathrm{kg} \mathrm{IV}$, seguido por $5 \mu \mathrm{g} / \mathrm{kg} / \mathrm{min}$ IV em infusão contínua, 30 minutos antes da indução da contusão medular, preveniu a diminuição do fluxo sangüíneo após lesão medular em gatos. Já a flunarizina $(0,1$ $\mathrm{mg} / \mathrm{kg}$ IV), administrada cinco e 120 minutos após contusão medular em gatos, resultou em recuperação de $52 \%$ dos potenciais evocados contra $17 \%$ nos gatos sem tratamento (MEINTJES; HOSGOOD; DANILOFF, 1996; LECOUTER, 1998). A combinação de metilprednisolona e flunarizina resultou na recuperação de $62 \%$ dos potenciais evocados. A flunarizina, neste estudo, não teve efeito significativo no fluxo sangüíneo medular após a lesão (LECOUTER, 1998).

Constatou-se que o aumento da concentração intracelular de cálcio depende do aumento das concentrações de sódio no axônio, e que o bloqueio de canais de sódio foi benéfico à recuperação de lesões axonais e metabólicas na substância branca do sistema nervoso central (SNC) (JEFFERY; BLAKEMORE, 1999). Após o uso do bloqueador de canais de sódio tetrodoxina, injetado diretamente no local de lesão medular experimental em ratos, verificou-se melhora significativa na recuperação funcional (TENG; WHATHALL, 1997). Infelizmente, esta substância mostrou-se muito tóxica para uso clínico, mas outros bloqueadores de canais de sódio como por exemplo o mexiletine, poderia produzir efeitos clínicos satisfatórios similares (JEFFERY; BLAKEMORE, 1999).

\section{Antioxidantes e varredores de radicais livres}

Agentes como as vitamina $\mathrm{C}$, E, selênio, coenzima $\mathrm{Q}$ e o dimetil sulfóxido (DMSO) têm o potencial de reduzir a magnitude da necrose tecidual após lesão, protegendo a medula espinhal dos efeitos deletérios dos radicais livres. (BRAUND, 1993). O selênio é um co-fator para a peroxidase glutationa, uma enzima que atua removendo o peróxido de hidrogênio intracelular (HALL; WOLF, 1986). As propriedades antioxidantes da vitamina E são creditadas à sua lipossolubilidade e capacidade de se intercalar entre os ácidos graxos poliinsaturados dos fosfolipídeos da membrana celular, protegendoa do ataque dos radicais livres (HALL; WOLF, 1986). $\mathrm{O}$ alfa-tocoferol (vitamina E) apresentou bons resultados ao ser administrado a gatos (1000 UI/dia), durante cinco dias, antes da indução do trauma medular, porém seu efeito ainda não foi estudado após a ocorrência da lesão medular (BERGMAN et al., 2000 a). Como é necessário intervalo de tempo longo para que esses antioxidantes atinjam níveis terapêuticos no SNC, seu uso após a ocorrência da lesão aguda à medula espinhal parece inviável (OLBY, 1999). Porém, cinco dias de pré-tratamento com vitamina $\mathrm{E}(1000 \mathrm{UI})$ e selênio $(50 \mu \mathrm{g})$ poderiam ser indicados antes da realização de cirurgias da coluna vertebral (OLBY, 1999)

Autores de estudos com o uso de microscopia eletrônica indicaram que o dimetil sulfóxido (DMSO), administrado uma hora após contusão medular em cães, protegeu a bainha de mielina e os axônios, reduziu o edema e acelerou o retorno da função motora (COUGHLAN, 1993; MEINTJES; 
HOSGOOD; DANILOFF, 1996). Entretanto, em gatos com trauma medular agudo, não foi observado diferença significativa da eficácia do DMSO entre os grupos de animais não tratados e tratados, quando estes últimos receberam tal droga nas seguintes dosagens: $1,5 \mathrm{mg} / \mathrm{kg}$ após 45 minutos e cinco horas da ocorrência da lesão; $1 \mathrm{mg} / \mathrm{kg}$ duas vezes ao dia (BID) iniciando 24 horas após a ocorrência da lesão; $0,7 \mathrm{mg} / \mathrm{kg}$ BID após dois dias da ocorrência da lesão e $0,5 \mathrm{mg} / \mathrm{kg}$ BID após três dias da ocorrência da lesão (HOERLEIN et al., 1985). Em cães, com trauma medular, constatou-se que na dosagem de $2 \mathrm{~g} / \mathrm{kg}$, o DMSO causou hemólise significativa, com diminuição do volume globular e decréscimo notório do fluxo sangüíneo na medula espinhal, fator prejudicial nos casos em que há isquemia (BERG; RUCKER, 1985; OLBY, 1999).

\section{Inibidores do metabolismo do ácido araquidônico}

Agentes que previnem ou antagonizam a formação de metabólitos vasoativos provenientes do ácido araquidônico, como as prostaglandinas e os tromboxanos, poderiam ter valor prático no tratamento da lesão aguda da medula espinhal. Os inibidores da ciclo-oxigenase, como ibuprofeno e meclofenamate, poderiam prevenir a isquemia medular após o trauma (BRAUND, 1993). A utilização destes agentes apresentou bons resultados em gatos, à medida que inibiu a diminuição do fluxo sangüíneo na medula espinhal após o trauma (JANSSENS, 1986).

\section{Barbitúricos}

O uso de barbitúricos após o trauma medular experimental em ratos foi benéfico, pois essa substância atuou no SNC diminuindo os níveis de potássio no local da lesão e o dano ao endotélio microvascular, com subseqüente redução da agregação plaquetária, atuando também na redução do edema vasogênico diminuindo os efeitos da peroxidação lipídica (COLTER; RUCKER, 1988).

\section{Antagonistas dos opióides}

A utilização de altas doses de naloxona após a ocorrência de trauma medular experimental em gatos, melhorou o fluxo sangüíneo medular, aumentando a recuperação da função neurológica (BRAUND, 1993; BERGMAN et al., 2000). Quando administrada uma a quatro horas após o trauma, mostrou alguns benefícios, sendo o efeito dose-dependente (BERGMAN et al., 2000 a). Ela atua revertendo a ação dos opióides, que quando em excesso elevam as endorfinas, resultando em hipotensão e redução do fluxo sangüíneo medular (MEINTJES; HOSGOOD; DANILOFF., 1996; BERGMAN et al., 2000 a). Quando administrada a gatos em infusão contínua por quatro horas, HOERLEIN et al. (1985) não observaram resultados significativos, quando comparado ao grupo controle. Sugeriu-se que a administração de antagonistas dos opióides logo após o trauma, em única dose, poderia proteger a medula durante o transporte do paciente até a realização do procedimento cirúrgico (BRAUND, 1993). Em humanos, a avaliação dos resultados do Segundo Consenso Nacional do Tratamento do Trauma Medular (EUA) não verificou benefícios com o uso de naloxona em pacientes que receberam este fármaco na dose de 5,4 mg/kg em bolus seguido por uma dose de manutenção em infusão contínua de 4,0 $\mathrm{mg} / \mathrm{kg} / \mathrm{hora}$ (BRACKEN et al., 1992; BERGMAN et al., 2000 a).

\section{Hormônio liberador da tirotropina}

O hormônio liberador da tirotropina (TRH) regula a liberação de secreções pituitárias de TSH (BERGMAN et al., 2000 a) e, no SNC, funciona como antagonista parcial de muitos efeitos dos opióides endógenos. O TRH também bloqueou a hipotensão induzida pelos leucotrienos (BRAUND, 1993) e inibiu o fator de ativação plaquetária. Em um estudo experimental em gatos, houve bons resultados quando administrado na dosagem de $2 \mathrm{mg} /$ kg IV, em infusão contínua, durante uma hora (BRAUND, 1993). Porém, este fármaco apresentou 
um tempo reduzido de meia-vida, devendo ser administrado dentro de uma hora após a ocorrência da lesão medular. Infelizmente, em humanos tratados com este medicamento os resultados foram insignificantes na melhoria da recuperação funcional (BERGMAN et al., 2000 a).

\section{Progesterona}

A progesterona foi efetiva no tratamento do trauma medular agudo em ratos, possivelmente devido ao efeito neuroprotetor, prevenindo a morte celular pela modulação do N-metil-D-aspartato (NMDA), um dos receptores do L-glutamato, um neurotransmissor excitatório. Ela diminuiu a gravidade da fase aguda da lesão espinhal, através da redução da permeabilidade da barreira hematoencefálica, possuindo efeitos antioxidantes e inibidores da peroxidação lipídica (BERGMAN et al., 2000 a).

\section{Antagonistas do NMDA}

Os bloqueadores de NMDA foram usados para inibir o potencial neurotóxico dos aminoácidos excitatórios como o glutamato (BERGMAN et al., 2000 a). $O$ aumento desses neurotransmissores na área da lesão medular pode ativar dois tipos de receptores excitatórios: o ácido propiônico $\alpha$-amino3-hidroxi-5-metil-4-isoxazole (AMPA) e o NMDA. Em alguns estudos em ratos observou-se redução da isquemia após lesão medular experimental, bloqueando a ativação dos dois receptores. Apenas o bloqueio do receptor NMDA não apresentou efeito benéfico (JEFFERY; BLAKEMORE, 1999). A utilização de antagonistas de NMDA, como o MK801, tienilfenciclidine e NBQX, em modelos de lesões espinhais isquêmicas, concussiva e compressiva em ratos, demonstra que, mesmo havendo melhora da recuperação funcional, estas drogas podem causar efeitos adversos, incluindo sedação, ataxia, estimulação motora e alterações cardiovasculares (OLBY, 1999).

\section{Glicocorticóides}

Os glicocorticóides são usados extensivamente desde 1960 no tratamento clínico do trauma medular, com o intuito de reduzir o edema, a inflamação e as lesões vasculares que ocorrem após o trauma agudo à medula espinhal (JEFFERY, 1995; MEINTJES; HOSGOOD; DANILOFF, 1996; SHARP ; WHEELER, 2005). Em dosagens mais altas, os corticóides parecem atuar melhorando o fluxo sangüíneo e protegendo o tecido neuronal contra os efeitos citotóxicos dos radicais livres (BRACKEN et al., 1992; BRAUND, 1993; MEINTJES; HOSGOOD; DANILOFF, 1996). Apesar do uso amplo e empírico dos corticóides, os benefícios deste fármaco são conflitantes. A avaliação dos seus efeitos torna-se complicada pela variação nas dosagens utilizadas, inclusive com espécies, momentos de administração e duração do tratamento diferentes (BRAUND, 1993), além de existirem controvérsias quanto a eficácia observada e mecanismo de ação (MEINTJES; HOSGOOD; DANILOFF, 1996; HURLBERT, 2000; STURGES; LECOUTER, 2002).

A dexametasona não demonstrou qualquer efeito benéfico na recuperação de lesões medulares agudas em gatos com lesão na segunda vértebra lombar recebendo a medicação na dosagem de $2,2 \mathrm{mg} / \mathrm{kg}$ a cada 12 horas, quando comparado com gatos que não foram submetidos ao tratamento (HOERLEIN et al., 1983). Sua utilização foi associada ao aparecimento de úlceras e hemorragias gastrointestinais, perfuração colônica, pancreatite, imunossupressão e morte (MEINTJES; HOSGOOD; DANILOFF, 1996). Devido à freqüência dos efeitos adversos e à incerteza de sua eficácia, o uso da dexametasona para o tratamento da lesão aguda à medula espinhal não é recomendado (MEINTJES; HOSGOOD; DANILOFF, 1996; LE COUTEUR, 1998; SHARP ; WHEELER, 2005).

O succinato sódico de metilpredinisolona (SSMP) é até o presente momento considerado o fármaco de eleição no tratamento da lesão medular aguda, devido 
aos seus efeitos neuroprotetores contra a cascata dos eventos secundários que se desenvolvem após o trauma medular (BRACKEN et al., 1992; BRAUND, 1993). O SSMP foi selecionado em detrimento de outros esteróides, pois o radical succinato atravessa as membranas celulares mais rapidamente do que outros radicais (BRACKEN et al., 1992). O mecanismo de ação do SSMP não ocorre pela sua atividade glicocorticóide (SHARP; WHEELER, 2005), mas pela inibição da peroxidação lipídica, prevenção da isquemia progressiva, diminuição da concentração de cálcio intracelular, prevenção da degradação do tecido nervoso e inibição da hidrólise lipídica da membrana celular, via ácido araquidônico e conseqüente formação da prostaglandina PGF $2 \alpha$ e tromboxano $\mathrm{A}_{2}$ (BRACKEN et al., 1992; HALL, 1992; MEINTJES; HOSGOOD; DANILOFF, 1996).

Estes efeitos do SSMP foram observados somente com dosagens altas $(30 \mathrm{mg} / \mathrm{kg})$, muito maiores do que a dosagem anti-inflamatória $(0,5 \mathrm{mg} / \mathrm{kg})$ (BRACKEN et al., 1992), que satura todos os receptores para glicocorticóides (SHARP; WHEELER, 2005). Preconiza-se sua administração dentro das primeiras 8 horas após o trauma, na dosagem de $30 \mathrm{mg} / \mathrm{kg}$, por via intravenosa (IV), seguida por infusão constante de $5,4 \mathrm{mg} / \mathrm{kg} / \mathrm{h}$ por 24 horas (BRACKEN et al., 1992; MEINTJES; HOSGOOD; DANILOFF, 1996); ou ainda em uma dosagem inicial de $30 \mathrm{mg} / \mathrm{kg}$, também dentro das primeiras 8 horas pós-trauma, seguida por duas outras doses de $15 \mathrm{mg} / \mathrm{kg}$, duas e 6 horas após a primeira dose, e posterior infusão constante de $2,5 \mathrm{mg} / \mathrm{kg} / \mathrm{h}$, por $18-24$ horas (BAGLEY et al., 1999; OLBY; JEFFERY, 2003). Em gatos com lesão em L2, tratados com este protocolo, o escore de avaliação neurológica foi melhor quando comparado ao grupo que recebeu placebo (MEINTJES; HOSGOOD; DANILOFF, 1996).

Segundo BRACKEN (1992), pacientes que iniciaram o tratamento com SMMP dentro de três horas após a lesão medular devem manter o tratamento por 24 horas e pacientes cujo tratamento foi iniciado três a oito horas após a lesão devem mantê-1o por até 48 horas para manter as concentrações teciduais do medicamento em níveis terapêuticos úteis para inibição do desenvolvimento de lesões secundárias (BERGMAN et al., 2000 a).

Existem muitas dúvidas sobre dosagem e freqüência de administração na medicina veterinária, visto que a posologia indicada é a mesma da espécie humana (OLBY, 2000; HURLBERT, 2000). Apesar das evidências de que o SSMP modifica o curso dos eventos após lesão medular aguda (MEINTJES; HOSGOOD; DANILOFF, 1996), existem muitas dúvidas também quanto a sua eficácia: a análise estatística utilizada nos consensos sobre o tratamento do trauma medular em humanos, a falta de padronização dos pacientes e os pontos de corte escolhidos estão sendo questionados (HURLBERT, 2000). Uma revisão extensa dos II e III Consensos concluiu que o uso do SSMP em humanos com lesão medular pode não ser recomendado, pois a evidência de sua eficácia é pequena (HURLBERT, 2000; STURGES; LECOUTER, 2002). No III consenso, observa-se uma taxa seis vezes maior de morte por complicações respiratórias quando se utiliza o SSMP por 48 horas, quando comparado ao protocolo de SSMP por 24 horas (COLEMAN et al., 2000). Os benefícios relatados originalmente foram para os membros superiores dos humanos, não tendo ocorrido retorno à deambulação (SHARP; WHEELER, 2005). Estas alterações mínimas são importantes para os seres humanos, mas sem significado para animais de companhia. Em seres humanos pode ser decorrente de melhora na função da substância cinzenta, mas nos animais a substância branca é mais importante (JEFFERY; BLAKEMORE, 1999; SHARP ; WHEELER, 2005).

COLEMAN et al. (2000) e HURLBERT (2000), na revisão destes consensos apontaram várias falhas relacionadas aos resultados alcançados com o uso do SSMP, como por exemplo: o momento da administração do medicamento para animais de laboratório ocorre minutos após a lesão e em seres humanos horas após; o modelo experimental não reproduz os padrões complexos vistos no paciente 
politraumatizado; os resultados dos consensos foram apresentados antes da publicação científica e antes da aprovação pelo Food and Drug Administration, havendo inadequação na estatística, falha na metodologia (grupos diferentes de pacientes, tornando impossível comparar os resultados) e na escolha da população que recebeu a medicação (mais da metade das pessoas que recebeu o medicamento estaria quase normal na admissão ao hospital). Os autores não afirmam que o SSMP seja ineficaz, mas não há como determinar sua eficácia somente com os resultados dos consensos (COLEMAN et al., 2000).

Ainda segundo HURLBERT (2000), todo fármaco deve cumprir alguns requisitos antes de ser aceito como padrão ouro: as evidências devem ser obtidas em um estudo prospectivo padronizado duplocego; o estudo deve ser bem delineado e executado; os dados devem ser convincentes e obtidos usandose métodos estatísticos apropriados; o estudo deve produzir mudanças significativas para o paciente e os resultados devem poder ser reproduzidos. Ao avaliar os dados do II e III consenso Nacional, HULBERT (2000) concluiu que apesar de bem delineados e executados, os consensos falharam em demonstrar benefícios do SMMP, pois não são convincentes, não são reproduzíveis, a estatística é falha e não tem impacto importante para os pacientes. Complementa ainda afirmando não haver evidência da eficácia do medicamento, que o SMMP não pode ser considerado padrão nem recomendado, e o tratamento por 48 horas não deve ser aplicado podendo ser prejudicial e até mesmo fatal. Qian, Campagnol e Kirshblum (2000) também questionam a administração do SMMP por 48 horas, argumentando que esta mega dosagem aumenta o risco de sepse, pneumonia e miopatia. A dose de 80 $\mathrm{mg} / \mathrm{kg} \mathrm{IV}$, administrada a ratos por cinco dias, pode induzir a perda grave de musculatura respiratória e esquelética e atrofia muscular, podendo levar ao quadro de miopatia corticosteróide aguda (QIAN; CAMPAGNOL; KIRSHBLUM, 2000), enquanto que a dose de $90 \mathrm{mg} / \mathrm{kg}$ promove peroxidação lipídica (MEINTJES; HOSGOOD; DANILOFF, 1996). além de aumentar os riscos de imunossupressão, alterações gastrintestinais, sepse, pneumonia e pancreatite (HULBERT, 2000; STURGES; LECOUTER, 2002).

Segundo SIEMERING; VROMAN (1992), em cães com doença de disco intervertebral toracolombar submetidos à cirurgia descompressiva, o uso do SSMP auxiliou na recuperação dos animais. $\mathrm{Na}$ experiência dos autores deste trabalho, cães com doença de disco toracolombar apresentando paraplegia com perda da sensibilidade profunda, submetidos à cirurgia descompressiva, ocorre recuperação da função neurológica mesmo sem o uso deste fármaco (BAHR ARIAS et al., 1999). O mesmo resultado foi relatado por BUSH et al. (2004), que obtiveram bons resultados após cirurgia descompressiva sem o uso deste fármaco em cães com DDIV toracolombar submetidos à laminectomia. Já segundo SIEMERING; VROMAN (1992), não houve efeitos colaterais após o uso de altas doses de SSMP em 86 cães com doença de disco intervertebral. Já em outro trabalho, 35 de 108 cães desenvolveram diarréia ou melena (CULBERT et al., 1998).

Relata-se ainda que a utilização de doses muito altas de SSMP pode interferir na proteção neuronal normal, pela inibição da atividade das células do sistema imunológico, incluindo os macrófagos. Neste caso haveria inibição do processo de regeneração neuronal e brotamento axonal (BRACKEN et al., 1993; MEINTJES; HOSGOOD; DANILOFF, 1996). Assim, embora este fármaco possa ser considerado um avanço no tratamento, deve ser usado com cautela (SHARP; WHEELER, 2005).

\section{Aminoesteróides}

Os 21-aminoesteróides ou lazaróides têm propriedades antioxidantes sem efeitos secundários nos receptores esteróides, sendo 100 vezes mais potentes que o SSMP na inibição da peroxidação lipídica (FRANCEL et al., 1993; MEINTJES; HOSGOOD; DANILOFF, 1996; LECOUTER, 
1998). O tirilazade é um 21-aminoesteróide desenvolvido para uso clínico (COUGHLAN, 1993; BERGMAN, et al. 2000 a), sendo efetivo nas reações catalizadas pelo ferro, além de inibir a ação dos radicais livres e dos metabólitos da peroxidação lipídica, promovendo a diminuição da quantidade de ácido araquidônico liberado no local do trauma (FRANCEL et al., 1993). Gatos com compressão medular experimental em L2 tratados com tirilazade apresentaram recuperação de $75 \%$ da função neurológica em quatro semanas (MEINTJES; HOSGOOD; DANILOFF, 1996). A medicação administrada a gatos com contusão medular induzida em L3, na dose de $3 \mathrm{mg} / \mathrm{kg}$ pela via intravenosa, quatro horas após a lesão reverteu parcialmente a isquemia medular (MEINTJES; HOSGOOD; DANILOFF, 1996). Em um modelo com coelhos albinos, o tirilazade foi administrado oito horas antes da indução da isquemia medular, observando-se melhora da perfusão medular. (FRANCEL et al., 1993). Entretando, quando COATES et al. (1995) testaram o aminoesteróide em 41 cães, nas dosagens de $30,15,10,5$ e $1,5 \mathrm{mg} / \mathrm{kg}$ pela via intravenosa, não observaram melhora na recuperação neurológica dos animais, quando comparados ao grupo controle. Isto mostrou que os benefícios obtidos com o uso do tirilazade não foram semelhantes aos obtidos com a administração de SSMP (BERGMAN et al., 2000 a). Além disso, a medicação não está disponível comercialmente no Brasil.

\section{Gangliosídeos}

Os gangliosídeos são constituintes das membranas celulares encontrados principalmente no SNC. Eles facilitam o crescimento dos axônios e a função dos neurônios após a lesão, e ampliam os tratos da substância branca (BERGMAN et al., 2000 a). Segundo OLBY (1999), os gangliosídeos (GM $)$ atenuam os efeitos dos aminoácidos excitatórios, indicando a possibilidade de possuírem ação neuroprotetora na lesão medular aguda. Em seres humanos, foram constatados efeitos benéficos quando administrado pelo menos 48 a 72 horas após a lesão, na dosagem de $100 \mathrm{mg}$ por dia, pela via intramuscular, durante três a quatro semanas (OLBY, 1999). Seu emprego juntamente com o SSMP apresentou bons resultados em humanos, quando estes receberam inicialmente o SSMP, e em seguida o $\mathrm{GM}_{1}(10 \mathrm{mg}$ por dia) durante 26 dias (BERGMAN et al., 2000 a). Entretanto, em ratos, não foi observado melhora, devido a possível antagonismo do efeito do SSMP pelo GM1 (OLBY, 1999). Em humanos, pode existir a associação da ocorrência da síndrome de GuillainBarré, uma polirradiculoneurite aguda, com a administração parenteral de gangliosídeos (BERGMAN et al., 2000 a). Chinnock \& Roberts (2005), ao avaliarem o uso dos gangliosídeos em seres humanos concluíram que não há qualquer evidência que comprove sua eficácia na recuperação da lesão medular.

\section{Opções Promissoras de Tratamento}

\section{Inibidores da caspase e da calpaina}

As caspases são importantes mediadoras da morte celular numa variedade de condições neurológicas (FINK et al., 1999). Seus inibidores mostraram-se alternativa promissora no tratamento do trauma medular, retardando a lesão celular e reduzindo o edema e a inflamação subseqüentemente ao trauma. A utilização de inibidores da caspase (BAF e AcYVAD-cmk) em ratos, preveniu a morte de diversos tipos celulares, inclusive neurônios (CHENG et al., 1998). É possível que a redução da inflamação e do edema cerebral tenha ocorrido secundariamente à inibição da caspase específica, com subseqüente diminuição na formação da interleucina $1 \beta$, principal responsável pelo desencadeamento do processo de apoptose celular (CHENG et al., 1998).

O inibidor da calpaína CEP 4143, quando utilizado diretamente na medula espinhal de ratos, por meio de microinjeções, antes da lesão aguda, possibilitou melhora significante da função neurológica seis semanas após o trauma. Houve inibição da ativação 
da calpaína, resultando em preservação do tecido adjacente ao local da lesão, sugerindo que os inibidores da calpaína são neuroprotetores eficientes, que futuramente poderão ser empregados como limitantes dos eventos secundários, após a lesão primária à medula espinhal (SCHUMACHER; 2000).

\section{Polietilenoglicol}

A solução de polietilenoglicol (PEG), utilizada na medula traumatizada de cobaias, promoveu recuperação imediata da condução dos impulsos nervosos e de algumas funções neurológicas próprias da substância branca. A medula espinhal das cobaias foi exposta durante a realização de procedimento cirúrgico e a solução de PEG foi diretamente aplicada 15 minutos após a lesão medular em um grupo e oito horas após a lesão medular em outro grupo (SHI; BORGENS; BLIGHT, 1999; BERGMAN et al., 2000 a). O PEG promoveu a conexão ou reconexão das membranas celulares, restaurando a excitabilidade da membrana e inibindo a destruição de axônios durante o processo de lesão secundária (BORGENS; SHI, 2000). Já em cães a utilização de PEG não apresentou bons resultados (BERGMAN et al., 2000 a). Este tratamento pode ser eventualmente empregado em associação à cirurgia descompressiva e a estabilização da coluna vertebral (BERGMAN et al., 2000 a).

\section{Sulfato de magnésio}

Em ratos apresentando contusão medular, observou-se que a administração de sulfato de magnésio $(100 \mathrm{mg} / \mathrm{kg}$ e $600 \mathrm{mg} / \mathrm{kg})$, pela via intraperitoneal, imediatamente após o trauma resultou em rápida recuperação funcional. $O$ sulfato de magnésio pode causar vasodilatação na medula espinhal, estimulando a liberação de prostaglandinas do endotélio dos vasos, podendo assim, inibir a peroxidação lipídica e prevenir trombose nos vasos do segmento atingido através da inibição da reativação plaquetária.
Os efeitos neuroprotetores do magnésio envolvem o bloqueio dos canais de cálcio regulados pelos receptores NMDA, a inibição da produção de lactato e a manutenção da integridade da membrana celular (KAPTANOGLU et al., 2003).

\section{Transplantes}

Os transplantes celulares representam uma alternativa promissora na recuperação funcional de pacientes vítimas de trauma medular. Muitas técnicas visam a reconstituição do tecido nervoso lesionado, através do implante de células diferenciadas, promovendo o desenvolvimento de um meio favorável à regeneração tecidual (JEFFERY et al., 2001).

A implantação de blocos de tecido do SNC fetal nas áreas de tecido nervoso lesado pode possibilitar o desenvolvimento de um meio favorável ao crescimento axonal (JEFFERY; BLAKEMORE, 1999). Células nervosas da bainha olfatória, encontradas no bulbo e nervo olfatórios, local de contínuo crescimento celular, utilizadas com o objetivo de promover regeneração axonal, funcionaram como suporte para a mielinização dos axônios contribuindo assim na recuperação neurológica de pacientes vítimas de lesão medular (JEFFERY et al., 2001). Outros tipos de células que podem ser transplantadas são as células de Schwann, visto que a regeneração axonal no sistema nervoso periférico ocorre mais facilmente devido a particularidades que poderiam ser aplicadas no sistema nervoso central (JEFFERY; BLAKEMORE, 1999).

As células-tronco representam hoje, outro tipo celular promissor, pela sua capacidade de crescer e se diferenciar em células que compõem os diferentes tecidos do organismo. São utilizadas em diversos estudos na espécie humana, com o objetivo de reconstituir a comunicação entre o cérebro e os membros (BLIGHT, 2000; JEFFERY et al., 2001), mas ainda são necessários muitos anos antes do transplante celular ser considerado uma possibilidade rotineira de tratamento. 


\section{Tratamento da Lesão Medular Crônica}

Os glicocorticóides podem ser utilizados em dose antiinflamatória no tratamento de condições crônicas que causam compressão à medula espinhal para redução do edema, diminuindo o efeito compressivo, apresentando ainda, efeito anti-prostaglandina (JEFFERY, 1995). Antiinflamatórios não esteroidais podem ser empregados como parte da terapia para animais que apresentam dor ou leve paresia, perda crônica da sensibilidade dolorosa profunda nos membros pélvicos ou aqueles cujos proprietários não autorizam o tratamento cirúrgico (JEFFERY, 1995 a; TOOMBS; WATERS, 2003). O maior problema do uso de antiinflamatórios não esteroidais (AINEs) é observado quando os mesmos não surtem efeito e o médico veterinário opta por utilizar em seguida os glicocorticóides, o que pode causar sérias complicações gastrintestinais com o uso seguido dessas duas drogas. Da mesma forma que os corticosteróides, a administração de AINEs deve ser cautelosa, visto que o alívio da dor pode levar à atividade excessiva do animal, resultando na exacerbação dos sintomas (COUGHLAN, 1993; JEFFERY, 1995 a). Opióides como morfina, oximorfina e butorfanol (WHELLER; SHARP, 1994) e a acupuntura (CHAN; LIN; ROGERS, 1996) são opções adequadas para o combate à dor.

Pode ser considerada também uma lesão medular crônica a seqüela do trauma medular meses ou anos após a lesão. Neste caso, em humanos, com o objetivo de facilitar a locomoção, são utilizados medicamentos que reduzem a espasticidade dos membros, como o blacofen, clonidina e a ciproheptadina (BAGLEY, et al., 1999). Estes medicamentos parecem estimular os receptores da medula espinhal, favorecer a plasticidade do SNC e melhorar a força muscular (BERGMAN et al., 2000 a). O 4-aminopiridine, pela capacidade de tratar falhas na condução nervosa em fibras desmielinizadas, ajudou a equilibrar o balanço iônico em axônios com transecção incompleta e melhorou a locomoção em humanos, um ano após a ocorrência da lesão (BLIGHT, 2000; BERGMAN et al., 2000 a).
Atualmente é aceito que a lesão medular crônica poderia se beneficiar dos mesmos medicamentos utilizados em doenças desmielinizantes como a esclerose múltipla. $\mathrm{O}$ tratamento da desmielinização crônica é fundamentado na existência de fibras nervosas sobreviventes na medula lesada, que poderiam ser remielinizadas por oligodendrócitos sob condições favoráveis criadas pela administração de medicamentos ou implantação de fatores tróficos (BLIGHT, 2000).

\section{Considerações Finais}

A lesão e a compressão à medula espinhal levam ao desenvolvimento de eventos vasculares, bioquímicos e inflamatórios que podem provocar danos irreversíveis ao parênquima neuronal. É considerada uma das desordens mais sérias e desafiantes devido ao risco de seqüelas e incapacidade permanente (BRAUND, 1993). O conhecimento e a compreensão dos transtornos fisiopatológicos que ocorrem após lesões da medula espinhal são fundamentais para a adoção de medidas adequadas para interromper a destruição progressiva do tecido nervoso, proporcionando assim a possibilidade de recuperação funcional do paciente. As pesquisas realizadas intensamente nesta área aumentaram a compreensão dos fenômenos e mecanismo básico de lesão medular, porém o desenvolvimento de novas terapias foi menos intenso (BLIGHT, 2000). São de extrema importância as pesquisas realizadas em todo o mundo visando o tratamento do trauma medular. O desafio é analisar os resultados destes estudos e testar a eficácia clínica dos diversos medicamentos, o que é extremamente difícil. A realização de pesquisa clínica nem sempre fornece todas as respostas, havendo inclusive resultados conflitantes.

O médico veterinário deve avaliar cuidadosamente as informações emergentes antes de aceitar uma nova forma de tratamento que gradativamente tornase padrão, mais pela força da tradição do que pela ciência (HURLBERT, 2000). Para melhorar o manejo 
clínico de cães com lesão medular aguda, existe a necessidade de estudos prospectivos padronizados rigorosos dos tratamentos existentes e novos (OLBY et al., 2001). O ideal para o manejo do trauma medular agudo ainda é o tratamento do $\mathrm{ABC}$ do trauma, ou seja, manutenção de vias aéreas, respiração, circulação, imobilização do paciente, oxigenação, manutenção da pressão sangüínea e imobilização da coluna vertebral quando indicado, utilizando-se com cautela os medicamentos (HURLBERT, 2000). Os médicos veterinários devem se unir para realizar estudos multicêntricos avaliando criticamente as informações geradas. Essas informações irão auxiliar não somente os pacientes veterinários, mas também os humanos (OLBY, 2000).

\section{Referências}

ANDERSON, D. K., DEMEDIUK P, SAUNDERS RD, DUGAN LL, MEANS ED, HORROCKS LA.Spinal cord injury and protection. Annals of Emergency Medicine, Lansing, v.14, p.816-820, 1985.

BAGLEY, R. S.; HARRINGTON, M. L., SILVER, G. M.; CAMBRIDGE, A. J. CONNORS, R. L.; MOORE, M. P. Exogenous spinal trauma: clinical assessment and initial management. Veterinary Neurology, v.21, n.12, p.1138$1143,1999$.

BAHR ARIAS, M. V.; ANDRADE, F. R.; BAHR, S. E.; BARROS, M. Y.; CAMPOS, S.; MORENO, K. Hemilaminectomia para tratamento da doença de disco toracolombar em cães. Estudo retrospectivo. In: CONGRESSO BRASILEIRO DA ANCLIVEPA, 20., 1999, Águas de Lindóia. Anais... Águas de Lindóia 1999. p.35.

BARTHOLDI, D.; SCHWAB, M. E. Expression of proinflammatory cytokine and chemokine mRNA upon experimental spinal cord injury in mouse: An in situ hybridization study. European Journal of Neuroscience, Oxford, v.9, p.1422-1438, 1997.

BERG, R. J.; RUCKER, N. C. Pathophysiology and medical management of acute spinal cord injury. Compendium on Continuing Education for the Practicing Veterinarian, Princeton, v.7, n.8, p.646-652, 1985.

BERGMAN, R.; LANZ, O.; SHELL, L. A review of experimental and clinical treatments for acute spinal cord injury. Veterinary Medicine, Chicago, p.855-866, 2000 a.
. Acute spinal cord trauma: mechanisms and clinical syndromes. Veterinary Medicine, Chicago, v.95, n.11, p.846-850, 2000 b

BLIGHT, A.R. New drugs for spinal trauma. In: AMERICAN COLLEGE OF VETERINARY INTERNAL MEDICINE FORUM, 18., 2000, Seattle. Proceedings... Seattle, 2000. p.292-293.

BORGENS, R. B.; SHI, R. Immediate recovery from spinal cord injury through molecular repair of nerve membranes with polyethylene glycol. The FASEB Journal, Bathesda, v.14, p.27-35, 2000.

BRACKEN, M. B.; SHEPARD, M. J.; HOLFORD, T. R.; LEOSUMMERS L.; ALDRICH, E. F.; FAZL, M.; FEHLINGS, M.; HERR, D. L.; HITCHON, P. W.; MARSHALL, L. F.; NOCKELS, R. P.; PASCALE, V.; PEROT, P.L.; PIEPMEIER, J.; SONNTAG, V. K. H.; WAGNER, F.; WILBERGER, J. E.; WINN, H. R.; YOUNG, W. Administration of methylprednisolone for 24 or 48 hours or tirilazad mesylate for 48 hours in treatment of acute spinal cord injury: results of the third national acute spinal cord injury randomized controlled trial. Journal of the American Medical Association, Chicago, v.277, n.20, p.1597-1604, 1992.

BRACKEN, M. B.; HOLFORD, T. R. Effects of timing of methylprednisolone or naloxone administration on recovery of segmental and long-tract neurological function in NASCIS 2. Journal of Neurosurgery, Charlottesvile, v.79, p.500-507, 1993.

BRAUGHLER, J. M.; HALL, E. D. Central nervous system trauma and stroke. 1. Biochemical considerations for oxygen radical formation and lipid peroxidation. Free Radical Biology and Medicine, New York, v.6, p.289-301, 1989.

BRAUND, K. G. Acute spinal cord trauma. In: BOJRAB, M. S.; et al. Diseases mechanisms in small animal surgery. 2.ed. Lippincott: Williams \& Wilkins, 1993. Cap. 152, p.11401157.

Spinal trauma. In: Clinical syndromes in veterinary neurology. 2.ed. St. Louis: Mosby, 1994. Cap.3, p.261-266.

BRAUND, K. G.; SHORES, A.; BRAWNER, JR. W. R. The etiology, pathology, and pathophysiology of acute spinal cord trauma. Veterinary Medicine, Chicago, v.85, p.684691, 1990.

BUSH, W.W.; TICHES, D.M.; KAMPRAD, C.M.; BARR, C.S.; MURTAUGH, R.J. Results of laminectomy without methylprednisolone sodium succinate for acute thoracolumbar disk disease in 51 non-ambulatory dogs. 
Proceedings of International Veterinary Emergency and Critical Care Symposium, San Diego, California, 2004. Diponível em: <http://www.vin.com/Members/ Proceedings.plx?CID=IVECCS2004;PID=pr07390;> Acesso em: 05 out. 2005.

CAMBRIDGE, A. J.; BAGLEY, R. S. Traumatismo espinal: evaluación clínica e tratamiento. Waltham Focus, London, v.7, n.3, p.20-26, 1997.

CHAN, W.; LIN, J. H.; ROGERS P. A. M. A review of acupuncture therapy of canine paralysis and lameness. Veterinary Bulletin, Farnham Royal, v.66, n.10, p.999-1011, 1996.

CHENG, Y, DESHMUKH, M.; D'COSTA, A.; DEMARO, J. A.; GIDDAY, J. M.; SHAH, A.; SUN, Y.; JACQUIN, M. F.; JOHNSON, E. M.; HOLTZMAN, D. M. Caspase inhibitor affords neuroprotection with delayed administration in a rat model of neonatal hypoxic-ischemic brain injury. The Journal of Clinical Investigation, New York, v.101, n.9, p.1992-1999, 1998.

CHINNOCK, P.; ROBERTS, I. Gangliosides for spinal cord injury. Cochrane Database System Review, v.2, [online], disponível em: http://www.mrw.interscience.wiley.com/ cochrane/clsysrev/articles/CD004444/frame.html, 2005.

COATES, J. R.; SORJONEN, D. C.; SIMPSON, S. T., COX, N. R.; WRIGHT, J. C., HUDSON, J. A.; FINN-BODNER, S. T.; BROWN, S. A. Clinicopathologic effects of a 21aminosteroid compound (U74389G) aand high-dose methylprednisolone on spinal cord function after simulated spinal cord trauma. Veterinary Surgery, Philadelphia, v.24, p.128-139, 1995.

COLEMAN, W. P.; BENZEL D.; CAHILL, D. W.; DUCKER, T.; GEISLER, F.; GREEN, B.; GROPPER, M. R.; GOFFIN, J.; MADSEN, P. W.; MAIMAN, D. J.; ONDRA, S. L.; ROSNER, M.; SASSO, R. C.; TROST, G. R.; ZEIDMAN, S. A critical appraisal of the reporting of the national acute spinal cord injury studies (II and III) of methylprednisolone in acute spinal cord injury. Journal of Spinal Disorders, Hagerstown, v.13, n.3, p.185-199, 2000.

COLTER, S; RUCKER, N. C. Acute injury to the nervous system. Veterinary Clinics of North American. Small Animal Practice, Philadelphia, v.18, n.3, p.545-563, 1998.

COUGHLAN, A. R. Secundary injury mechanisms in acute spinal cord trauma. Journal of Small Animal Practice, Oxford, v.34, p.117-122, 1993.

CULBERT, L. A.; MARINO, D. J.; BAULE, R. M.; VANKNOX, I. W. Complications associated with high-dose prednisolone sodium succinate therapy in dogs with neurological injury. Journal of the American Animal Hospital Association, Lakewood, v.34, p.129-134, 1998.
DUSART, I.; SCHWAB, M. E. Secondary cell death and the inflammatory reaction after dorsal hemisection of the rat spinal cord. European Journal of Neuroscience, Oxford, v.6, p.712-724, 1994.

FINK, K. B.; ANDREWS, L. J.; BUTLER, W. E.; ONA, V. O.; LI, M.; BOGDANOV, M.; et al. Reduction of posttraumatic brain injury and free radical production by inhibition of the caspase- 1 cascade. Neuroscience, Oxford, v.94, n.4, p.1213-1218, 1999.

FRANCEL, P. C.; LONG, B. A.; MALIK, J. M.; TRIBBLE, C.; JANE, J. A.; KRON, I. L. Limiting ischemic spinal cord injury using a free radical scavenger 21-aminosteroid and/ or cerebrospinal fluid drainage. Journal of Neurosurgery, Charlottesville, v.79, p.742-751, 1993.

HALL, E. D. The neuroprotective pharmacology of methylprednisolone. Journal of Neurosurgery, Charlottesville, v.76, p.13-22, 1992.

HALL, E.D.; WOLF, D.L. A pharmacological analysis of the pathophysiological mechanisms of posttraumatic spinal cord ischemia. Journal of Neurosurgery, Charlottesville, v.64, p.951-961, 1986.

HOERLEIN, B. F., REDDING, R.W.; HOFF, E.J.; Mc GUIRE, J.A. Evaluation of naloxone, crocetin, thirotropin releasing hormone, methylprednisolone, partial myelotomy and hemilaminectomy in the treatment of cute sapinal cord trauma. Journal of the American Animal Hospital Association, Lakewood, v.21, p.67-77, 1985.

. Evaluation of dexamethasone, DMSO, mannitol and solcoseryl in acute spinal cord trauma. Journal of the American Animal Hospital Association, Lakewood, v.19, p.216-26, 1983.

HURLBERT, R. J. Methylprednisolone for acute spinal cord injury: an inappropriate standard of care. Journal of Neurosurgery Spine, Charlottesville, v.93, p.1-7, 2000.

JANSSENS, L. A. A. Mechanical and pathophysiological aspects of acute spinal cord trauma. Journal of Small Animal Practice, Oxford, v.32, p. 527-579, 1991.

Therapeutic aspects of acute spinal cord trauma. Journal of Small Animal Practice, Oxford, v.32, p. 620626, 1986.

JEFFERY, N. D. Medical and conservative therapy. In: Handbook of small animal spinal surgery. London: Saunders, 1995. Cap.15, p.215-221 a.

Pathophysiology of spinal cord injury. In: Handbook of small animal spinal surgery.

London: Saunders, 1995. Cap.5, p.64-71 b.

JEFFERY, N. D.; BLAKEMORE, W. F. Spinal cord injury in small animals. 2. Current and future options for therapy. Veterinary Record, London, v.145, n.7, p.183-190, 1999. 
JEFFERY, N.; PENDERIS, J.; SMITH, P.M.; FRANKLIN, R.J. Bridging the divide: spinal cord repair by cellular transplantation-from research laboratory to therapeutic application. Journal of Small Animal Practice, Oxford, v.42, p.428-432, 2001.

JERRAM, R. M.; DEWEY, C. W.: Acute thoracolumbar disk extrusion in dogs-part II. Compendium on Continuing Education for the Practicing Veterinarian, Princeton, v.21, p.1037-1046, 1999.

KAPTANOGLU, E.; BESKONAKLI E.; OKUTAN, O.; SELCUK SURUCU, H.; TASKIN, Y. Effect of magnesium sulphate in experimental spinal cord injury: evaluation with ultrastructural findings and early clinical results. Journal of Clinical Neuroscience, Churchill Livingstone, v.10, n.3, p.329-334, 2003.

KRAUS, K. H. Medical management of acute spinal cord disease. In: KIRK, R. W. Current veterinary therapy XIII: small animal practice. Philadelphia: Saunders, 2000. p.186190.

LANZ, O.; BERGMAN, R.; SHELL, L. Inicial assessment of patients with spinal cord trauma. Veterinary Medicine, Lenexa, v.95, p.851-853, nov. 2000.

LECOUTEUR, R. A. Spinal cord and vertebral column trauma. In: INTERNATIONAL VETERINARY AND CRITICAL CARE SYMPOSIUM, 6., 1998, San Antonio. Proceedings... San Antonio: IVECCS, 1998. p.291-295.

LI, G. L.; BRODIN, G.; FAROOQUE, M. et al. Apoptosis and expression ao $\mathrm{Bcl}-2$ after compression trauma to rat spinal cord. Journal of Neuropathology \& Experimental Neurology, Pittsburgh, v.55, p.280-289, 1996.

MEINTJES, E.; HOSGOOD, G.; DANILOFF, J. Pharmaceutic treatment of acute spinal cord trauma. Compendium on Continuing Education for the Practicing Veterinarian, Princeton, v.18, n. 6, p. 625-635, 1996.

OLBY, N. Current concepts in the management of acute spinal cord injury. Journal of Veterinary Internal Medicine, Lawrence, v.13, p.399-407, 1999.

. Clinical trials in spinal cord injury. AMERICAN COLLEGE OF VETERINARY INTERNAL MEDICINE, 18., 2000, Seattle. Proceedings... Seattle, 2000. p.287-289.

OLBY, N.; DE RISIO, L.; MUÑANA, K. R.; WOSAR, M. A.; SKEEN, T. M.; SHARP, N. J. H.; KEENE, B. W. Development of a functional scoring system in dogs with acute spinal cord injuries. American Journal of Veterinary Research, Chicago, v.62, n.10, p.1624-8, 2001.
OLBY, N.; JEFERRY, N. Pathogenesis of diseases of the central nervous system. In: SLATTER, D. Textbook of Small Animal Surgery. 2.ed. Philadelphia: Saunders, 2003. Cap.77, p.1132-1147.

PLATT, S. R.; ABRAMSON, C. J.; GAROSI, L. S. Administering corticosteroids in neurologic diseases. Compendium on Continuing Education for the Practicing Veterinarian, Princeton, v.27, n.3, p.210-220, 2005.

QIAN, T.; CAMPAGNOLO, D.; KIRSHBLUM, S. Highdose methylprednisolone may do more harm for spinal cord injury. Medical Hypotheses, v.55, n.5, p.452-453, 2000.

RUCKER, N. C. Management of spinal cord trauma. Progress in Veterinary Neurology, Santa Barbara, v.1, n.4, p.397-412, 1990.

SCHUMACHER, P. A. Pretreatment with calpain inhibitor CEP-4143 inhibits calpain I activation and cytoskeletal degradation, improves neurological function, and axonal survival after traumatic spinal cord injury. Journal of Neurochemistry, Oxford, v.74, n.4, p.1646-1966, 2000.

SHARP, N. J. H.; WHEELER, S. J. Small animal spinal disorders: diagnosis and surgery. 2.ed. Edinburgh: Elsevier Mosby, 2005.

SHI, R.Y.; BORGENS, R. B.; BLIGHT, A. R. Functional reconnection of severed mammalian spinal cord axons with polyethylene glycol. Journal of Neurotrauma, New York, v.16, n.18, p.727-738, 1999.

SHORES, A. Fractures and luxations of the vertebral column. Veterinary Clinics of North American: Small Animal Practice, v.22, n.1, p.171-180, 1992.

SHORES, A.; BRAUND, K. G.; BRAWNER, W. R. Management of acute spinal cord trauma. Veterinary Medicine, Chicago, v.85, p.724-739, 1990.

SIEMERING, G. B.; VROMAN, M. L. High dose methykprednisolone sodium succinate: an adjunct to surgery in canine intervertebral disc herniation. Scientific Meeting Abstract. Veterinary Surgery, Philadelphia, v.21, p.406, 1992.

SMITH, K. J.; McDONALD, W. I. The pathophysiology of multiple sclerosis: The mechanisms underlying the production of symptoms and the natural history of the disease. Philosophical Transactions of the Royal Society Biological Sciences, v.354, p.1649-1658, 1999.

STURGES, B. K.; LECOUTEUR, R. A. Vertebral fractures and luxations. In: SLATTER, D. Textbook of small animal surgery. 2.ed. Philadelphia: Saunders, 2002. Cap. 83, p.12441259. 
TENG, Y. D, WRATHALL, J. R. Local blockage of sodium channels by tetrodotoxin amelioratesntissue loss and long-term functional deficits resulting from experimental spinal cord injury. Journal of Neuroscience, Baltimore, v.17, p.4359-4366, 1997.

TOOMBS, J. P.; WATERS, D. J. Intervertebral disc disease. In: SLATTER, D. Textbook of small animal surgery. 2.ed. Philadelphia: Saunders, 2003. Cap. 80, p.1193-1209.
VANDEVELDE, M.; WOLF, M. Spinal cord compression. In: BOJRAB, M. S. Diseases mechanisms in small animal surgery. 2.ed. Lippincott: Williams \& Wilkins, 1993. Cap.153, p.1152-1156.

WHELLER, S.J.; ; SHARP, N.J.H. Small animal spinal disorders. Diagnosis and surgery. London, Mosby-Wolfe Publishing, 1994, 224p. 